\title{
The Standomobile: a new, electrically powered, mobile stand up device for use in paraplegia. Case report
}

\author{
J P van den Berg MD, ${ }^{1}$ A den Ouden, ${ }^{2} \mathrm{H} \mathrm{J}$ Stam MD $\mathrm{PhD}^{1}$ \\ ${ }^{1}$ Department of Rehabilitation, University Hospital Rotterdam, Dr. Molewaterplein 40, \\ 3015 GD Rotterdam, The Netherlands. ${ }^{2}$ Central Research Workshop, Erasmus University \\ Rotterdam, Dr. Molewaterplein 50, 3015 GE Rotterdam, The Netherlands.
}

\begin{abstract}
In this case study a specially designed electrically powered mobile stand up device, for a patient with a complete spinal cord lesion under cervical level C7, is described. It has proved to be satisfactory in a flower nursery, where both sitting and standing work is done. It is a usable aid to help patients to return to their work environment.
\end{abstract}

Keywords: spinal cord injury; paraplegia; device; the Standomobile; work.

\section{Introduction}

Patients with a spinal cord injury (SCI) are not capable of rising up independently. Most such patients are confined to a wheelchair.

Standing in the upright position is thought to aid in the reduction of osteoporosis and the prevention of renal calculi, the maintenance of vascular tone, the preservation of morale, the shifting of weight bearing to relieve pressure, reduction of spasticity and the prevention of contractures (to maintain a normal range of motion).$^{1,2}$

Commercially available stand up chairs are used for the above mentioned reasons, for activities of daily life and sometimes for work. Our opinion is that these chairs are not stable and flexible enough to function properly in working environments, where the patient requires sufficient support to work for several hours in a standing position, enabling the upper part of the body to move freely in every direction, to enlarge the persons work area.

In this case study we describe a new, specially designed electrically powered, mobile stand up device, for use in paraplegia, that fulfils the requirements of independent transfers, sufficient support, stability and flexibility for work in a flower nursery.

\section{Case report}

Patient $\mathrm{A}$ is a 23 year old man, co-owner of a flower nursery. In 1987 he was involved in a severe car accident resulting in a complete spinal cord lesion distal to cervical level C7, due to a double hooking of C7-T1. Because of this spinal cord lesion he had total paralysis of the legs, total anaesthesia below level C7, slight paresis of the flexor digitorum profundus, paralysis of the intrinsic hand muscles and disturbed balance.

After concluding the rehabilitation period, he wished to resume his former job as a nursery worker. The old company building that he used to work in was sold and a new building was bought, specially designed for wheelchair use. $\mathrm{He}$ required an electrical stand up device to function optimally, to permit him to perform both sitting and standing work. For these reasons such an electrical stand up device must meet the following requirements:

1 Adequate support for the body to work for several hours in a standing position, whereby the upper part of the body must be free to move in every direction.

2 Independent transfer from wheelchair to the stand up device and independent transfer from the stand up device to the wheelchair.

3 Independent ability to rise, to stand up and to sit down in the stand up device.

4 Electrically powered manoeuvering and driving over small distances. 
5 The controller of the electrical device must be reachable from the wheelchair and from the standing position.

\section{Materials and methods}

Based on these requirements an electrical stand up device was designed and built in the central research workshop of the Rotterdam Erasmus University (Fig 1).

For support while standing we used a commercially available standing up aid called the 'flexor major'. (Manufacturer: Camp Products, supplied by Ellis, Son and Paramore Ltd, Spring Streetworks, Sheffield S38PB, England). The advantage of this aid is the flexible mounted pole, which allows the user to enlarge the working range through trunk movements (left/right/ forward/backwards). This particular patient, however, being a tall, heavy man, the 'flexor major' had to be strengthened in several places.

The platform of the Standomobile is U-shaped, allowing the wheelchair to be

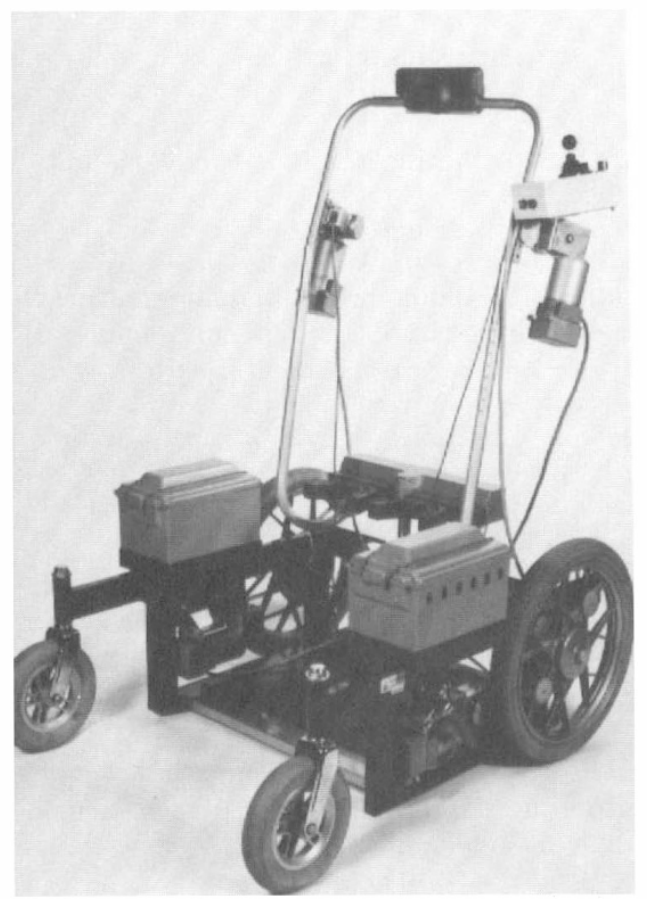

Figure 1 The Standomobile. driven into the space between the arms of the U. This enables the user to place his feet in the footrest of the device, so that an independent transfer from wheelchair to the device and back again can be made. The width of the stand up device is $86 \mathrm{~cm}$ and the placement of the swivelling wheels is at the rear of the device (Fig 2).

For the vertical movement of the body to rise, to stand and to sit down, two standard electrical motors with reduction gears are used. On the outgoing axle of the motors, a corddrum with a Keflar rope $(5 \mathrm{~mm}$ in diameter) is mounted.

The user wears a windsurfer trapeze to which the ropes can be connected with snap fittings. The windsurfer trapeze gives good support during lifting and standing and is easy to put on and to take off.

The propulsion and steering (control) has been taken from the available standard electrical wheelchair. The advantage of standard parts for propulsion and steering is the economy of space and the convenience of easy repair in case of failure. The user has

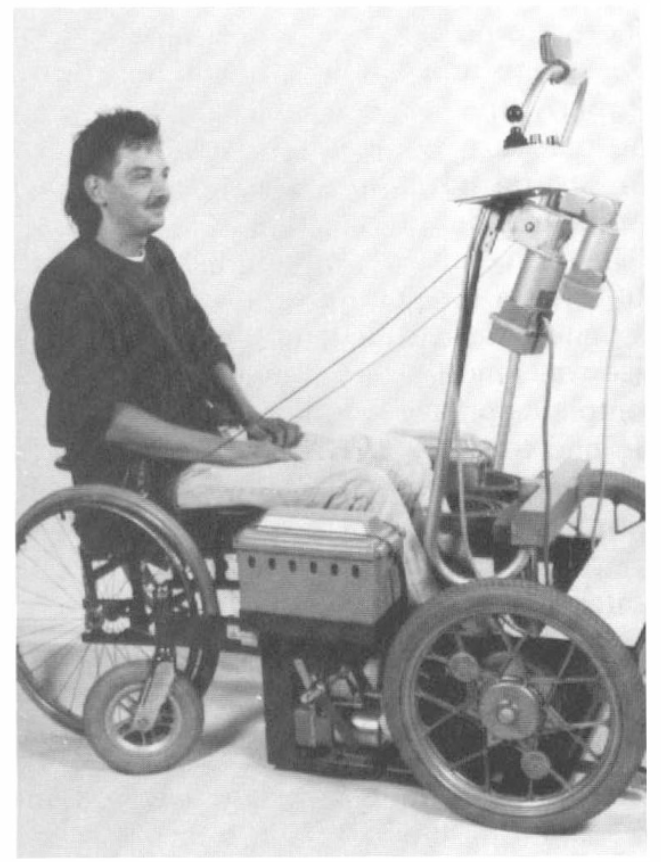

Figure 2 Wheelchair in position between the wheels of the stand up device. 
to stand as far as possible to the front of the stand up device, to make the work range as large as possible (Fig 3). For extra stability the heavy traction batteries are placed as far as possible back on the stand up device. Transfer from stand up chair to wheelchair requires some training in steermanship, to drive backwards with the stand up chair around the wheelchair.

Driving is by use of a joystick, which is currently used on many standard wheelchairs. Two position switches are placed to control the maximum speed and steering reaction.

The lifting is also controlled by the joystick; the height of the motors with regard to the body of the user is very crucial: too low means that the windsurfer trapeze will be pulled from under the user before he is lifted, too high will result in insufficient support while standing.

\section{Discussion}

All available stand up chairs or devices are mainly used for medical reasons (prevention of osteoporosis etc) and for extending the independence of activities of daily life..$^{1.2}$ There are no electrical stand up chairs that are strong and stable enough to function properly in working environments where the person needs enough support to work for several hours in a vertical postion and for independent tranfers.

In the central research workshop of the Rotterdam Erasmus University a specially designed electrically powered stand up device was made for a 23 year old man with a complete spinal cord injury level below $\mathrm{C} 7$. $\mathrm{He}$ had to work in a flower nursery, doing both sitting and standing work. After a learning period of a few weeks there were

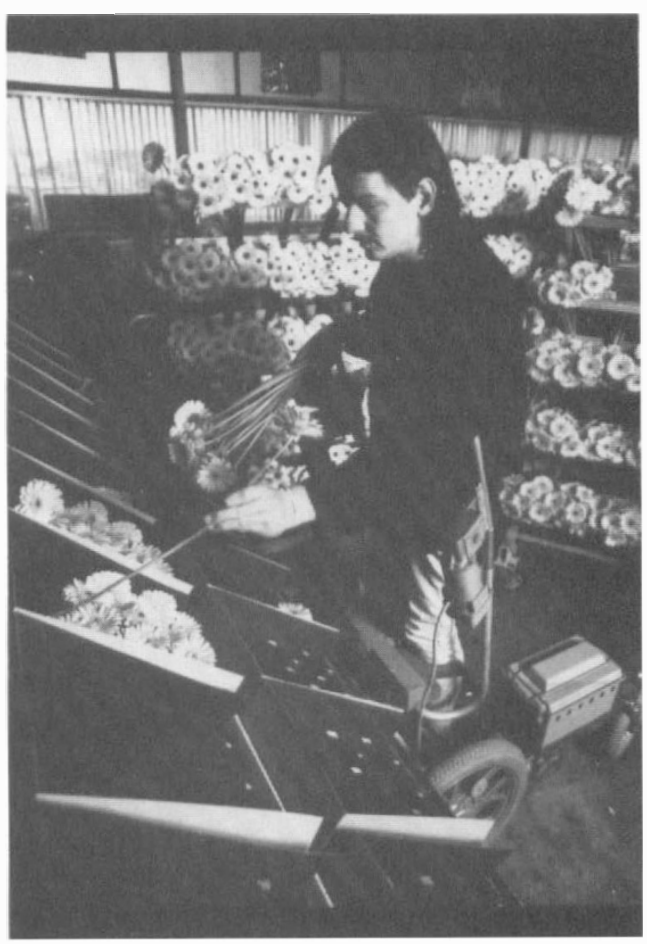

Figure 3 Patient standing in the Standomobile.

no problems operating the Standomobile. The specially designed electrical stand up device was used for several months in his flower nursery and has proved to be satisfactory for the patient. There were no problems with transfers, lifting, standing up, driving and using the electrical operation of the stand up chair. It is therefore an usable aid to help patients in returning to their work environment.

The central research workshop of the Erasmus University can make this device for about fl. 60.000, including research costs.

\section{References}

1 Kunkel CF, Scremin AML, Eisenberg B, Garcia JF, Roberts S, Martinez S (1993) Effect of 'standing' on spasticity, contracture, and osteoporosis in paralyzed males. Arch Phys Med Rehabil 74: 73-78.

2 Freed MM (1990) Traumatic and congential lesions of the spinal cord. In: Krusen FH, editor Handbook of Physical Medicine and Rehabilitation. W B Saunders Co, London: 643-673. 